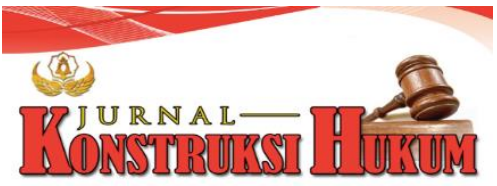

\title{
PERAN ANGGOTA KEPOLISIAN DALMAS POLDA BALI DALAM PENEGAKAN HUKUM TERHADAP PENANGANAN UNJUK RASA TOLAK REKLAMASI TELUK BENOA
}

\author{
I Kadek Windi Pranata Putra, Ida Ayu Putu Widiati, I Nyoman Gede Sugiarta \\ Fakultas Ilmu Hukum Universitas Warmadewa, Denpasar - Bali, Indonesia
}

\begin{abstract}
Abstrak
Setiap warga negara berhak untuk mengemukakan pendapat sesuai dengan Undang-undang Nomor 9 Tahun 1998 tentang Kemerdekaan Menyampaikan Pendapat di Muka Umum. Kebebasan berpendapat umumnya dilakukan dengan unjuk rasa.Unjuk rasa yang baru-baru ini ada di Bali adalah unjuk rasa tolak reklamasi Teluk Benoa. Hal ini menjadi perhatian khsusus bagi anggota Dalmas Polda Bali selaku pihak utama dalam penanganan unjuk rasa ini. Dalam penanganannya, Dalmas Polda Bali dituntun untuk menegakkan hukum terhadap setiap aksi unjuk rasa ini. Berdasarkan latar belakang tersebut, penelitian ini dilakukan dengan tujuan mendeskripsikan bagaimana peran anggota kepolisian Dalmas Polda Bali dalam penegakan hukum terhadap aksi unjuk rasa tolak reklamasi Teluk Benoa dan faktor-faktor apa yang menghambat pelaksanaan penanganan unjuk rasa tolak reklamasi Teluk Benoa oleh anggota Kepolisian Dalmas Polda Bali. Penelitian ini menggunakan metode penelitian hukum empiris. Hasil penelitian ini menunjukkan bahwa peran Kepolisian Dalmas Polda Bali dalam menegakan hukum terhadap aksi unjuk rasa tolak reklamasi Teluk Benoa dilakukan berdasarkan tindak pre-emtif, preventif serta tindakan represif yang berpedoman pada peraturan perundangundangan serta peraturan-peraturan Kapolri tentang penanganan unjuk rasa. Selain itu, faktor-faktor yang menghambat pelaksanaan unjuk rasa tolak reklamasi Teluk Benoa oleh anggota kepolisian Dalmas Polda Bali meliputi faktor internal dan eksternal. Faktor internal merupakan faktor dari anggota Dalmas sendiri baik dari segi mental, profesionalisme, maupun pengetahuan mengenai penangann unjuk rasa. Sedangkan faktor eksternal umumnya berupa massa pengunjuk rasa yang kurang memahai ketentuan-ketentuan yang berlaku dalam pelaksanan unjuk rasa.
\end{abstract}

Kata Kunci: Kepolisian Dalmas Polda Bali; Penanganan; Reklamasi; Unjuk Rasa

\begin{abstract}
Every citizen has the right to express an opinion in accordance with Law Number 9 of 1998 concerning Freedom of Expressing Opinions in Public. Freedom of opinion is generally carried out by demonstrations. The recent demonstration in Bali is a demonstration against the reclamation of Benoa Bay. This is of particular concern to members of the Bali Police Dalmas as the main party in the handling of this demonstration. In handling it, the Bali Police Dalmas is guided to enforce the law against each of these demonstrations. Based on this background, this research was conducted with the aim of describing how the role of members of the Bali Police Dalmas police in law enforcement against the Benoa Bay protest against the Benoa Bay reclamation and what factors hindered the implementation of handling the Benoa Bay reclamation protest action by members of the Bali Police Dalmas. This study used an empirical legal research method. The results of this study indicated that the role of the Bali Police Dalmas in enforcing the law against the protest against Benoa Bay reclamation was carried out based on pre-emptive, preventive, and repressive actions based on statutory regulations and the police chief regulations regarding the handling of demonstrations. In addition, the factors that hindered the implementation of the protest against the reclamation of Benoa Bay by members of the Bali Police Dalmas include internal and external factors. the internal factor is factor of Dalmas members themselves, both from a mental perspective, professionalism, and knowledge about how to handle protests. Meanwhile, the external factor is generally the mass of protesters who do not understand the provisions that apply to the implementation of a demonstration.
\end{abstract}

Keywords: Bali Mass Control Police; Handling; Reclamation; Demonstrations 


\section{PENDAHULUAN}

Landasan ideologi mengarah pada kuatnya penerapan demokrasi. Hal ini ditandai dengan adanya perlindungan hukum untuk warga negara yang mengemukakan pendapat yang dirumuskan dalam Pasal 28 Undang-undang Dasar Negara Republik Indonesia tahun 1945, bahwa kemerdekaan berserikat dan berkumpul mengeluarkan pikiran dengan lisan dan tulisan yang ditetapkan dengan Undang-Undang yang selanjutnya ditegaskan dalam pasal 28 F UUD 1945 yang menyebutkan "Setiap orang berhak untuk berkomunikasi dan memperoleh informasi untuk mengembangkan pribadi dan lingkungan sosialnya, serta berhak untuk mencari, memperoleh, memiliki, menyimpan, mengolah, dan menyampaikan informasi dengan menggunakan segala jenis saluran yang tersedia ".

Kebebasan menyampaikan pendapat ini dikembangkan kembali dalam Undang-Undang No. 9 Tahun 1998 tentang Kemerdekaan Menyampaikan Pendapat di Muka Umum (Syamsir, 2015). Kemerdekaan ini terlihat pada Pasal 1 Angka 1 yang menyatakan bahwa "Kemerdekaan menyampaikan pendapat adalah hak setiap warga negara untuk menyampaikan pikiran dengan lisan, tulisan dan sebagainya, secara bebas dan bertanggung jawab sesuai dengan ketentuan peraturan perundang-undangan yang berlaku". Dalam pelaksanannya, penyampaian pendapat ini tidak selamanya berjalan dengan aman serta tertib kadang kala terjadi berbagai bentuk pelanggaranpelanggran yang berujung pada tindakan anarkis yang tentunya perlu mendapat perhatian lebih oleh pihak kepolisian (Surawan, 2016; Syahbana, 2013). Ini umumnya dilakukan pada saat penyampaian pendapat melalui demontrasi atau unjuk rasa.

Di Bali sendiri demontrasi atau unjuk rasa sudah menjadi pemberitaan rutin di kalangan masyarakat. Demonstrasi atau unjuk rasa yang hampir setiap bulan terajadi di kalangan masyarakat Bali adalah demonstrasi tolak reklamasi Teluk Benoa oleh kelompok persatuan masyarakat Bali yang menamakan dirinya masa For Bali. For Bali adalah persatuan masyarakat Bali yang memiliki kepedulian terhadap lingkungan Bali serta meyakini bahwa Reklamasi Teluk Benoa dianggap dapat menghancurkan lingkungan Bali. Disebut dapat menghancurkan Bali karena Kawasan teluk Benoa dilingkari hutan mangrove yang berfungsi sebagai perlindungan terhadap gelombang air laut yang besar dari semenanjung Jimbaran bagian barat, dan bila reklamasi ini di lakukan maka dapat menghancurkan ekosistem maupun hidrologi Kawasan Tanjung Benoa. Selain itu, reklamasi ini juga berpengaruh terhadap perekonomian, sosial bidaya, dan keadaan lingkungan termasuk pasokan air di Kawasan Benoa dan sekitarnya (Sudiarta, Hendrawan, Putra, \& Dewantama, 2013).

Atas dasar itu mulailah timbul aksi penolakan terhadap proyek reklamasi yang datang dari berbagai elemen masyarakat di mana penolakan ini timbul mulai dari tahun 2012 hingga sekarang. Seiring dengan banyaknya kalangan masyarakat Bali menolak adanya Reklamasi teluk benoa menjadikan aksi ini sebagai perhatian khusus bagi kepolisian Polda Bali. Fungsi satuan polda Bali yang berperan langsug dalam penangan unjuk rasa adalah fungsi sabhara. Sabhara merupakan salah satu fungsi oprasioanl Polri yang memiliki tugas pokok dalam penanganan demontrasi atau unjuk rasa (pengendalian masa). Pasukan dalam pengendalian masa sendiri disebut sebagai anggota Dalmas Polri (Sutrisno, 2016).

Pergerakan demontrasi dan unjuk rasa tolak reklamasi teluk Benoa kerap kali menjadi kegiatan rutin bagi anggota Dalmas polri dalam memberikan pengamanan (Wiranata \& Siahaan, 2019). Pelaksanaan demontrasi teluk benoa yang di mulai sejak tahun 2012 hingga 2018 umumnya berjalan dengan aman serta jauh dari kata anarkis. Namun terdapat beberapa kegiatan demonstrasi yang luput dari pantaun kepolisian sehingga masa pengunjuk rasa melakukan tindakan yang melanggar ketentuan-ketentuan. Untuk menanggulangi hal tersebut, diperlukan kesadaran dari berbagai komponen masyarakat dalam pelaksanaan demontrasi atau unjuk rasa tolak reklamasi teluk benoa agar setiap tindakannya selalu mematuhi peraturan serta ketentuan-ketentuan yang berlaku. Setiap peraturan dan ketentuan-ketentuan tersebut manjadi tugas Dalmas Polda Bali sebagai penegak hukum terhadap aksi unjuk rasa tolak reklamasi Teluk Benoa. Penegakan hukum ini mengacu pada ketentuan-ketentuan dalam UU No. 9 tahun 1998 tentang Kemerdekaan Menyampaikan Pendapat yang penanganannya berpedoman pada Peraturan Kapolri No. Pol.: 16 Tahun 2006 tentang Pedoman Pengendalian Massa, Prosedur Tetap Nomor: PROTAP/1/X/2010 Penanggulangan Anarki serta Perkapolri No 9 Tahun 2008 Tentang Tata Cara Penyelenggaraan, Pelayanan, Pengamanan, dan Penanganan Perkara Penyampaian Pendapat di Muka Umum.

Berberapa penelitian terkait telah dilakukan sebelumnya, yaitu: pertama, penelitian yang dilakukan oleh Saputro (2015). Penelitiannya tersebut bertujuan untuk mengetahui penerapan diskresi 
anggota kepolisian dalam penanganan aksi unjuk rasa, terkait bentuk tindakan dan pertimbangannya serta kendala; dan implikasinya terhadap ketahanan wilayah. Selain itu, Yuliawati (2019) juga melakukan penelitian yang berkaitan dengan penelitian ini. penelitiannya berjudul 'Penegakan Hukum terhadap Aksi Unjuk Rasa Mahasiswa yang Menimbulkan Kerusakan pada Fasilitas Umum dalam Tinjauan Krimonologi'. Terakhir, Priyantoko (2016) meneliti tentang penerapan diskresi kepolisian dalam penanganan unjuk rasa yang juga berkaitan dengan penelitian ini.

Berdasarkan latar belakang yang telah diuraikan di atas, penelitian ini dilakukan dengan tujuan mendeskripsikan bagaimana peran anggota kepolisian Dalmas Polda Bali dalam penegakan hukum terhadap aksi unjuk rasa tolak reklamasi Teluk Benoa dan faktor-faktor apa yang menghambat pelaksanaan penanganan unjuk rasa tolak reklamasi Teluk Benoa oleh anggota Kepolisian Dalmas Polda Bali.

\section{METODE PENELITIAN}

Penelitian ini didesain dengan menggunakan metode penelitian hukum empiris. Karena penelitian ini meneliti orang dalam hubungan hidup di masyarakat, pendekatan masalah yang digunakan adalah pendekatan sosiologis hukum. Penelitian dilakukan di Kantor Kepolisian Direktorat Sabhara Subdit Dalmas Polda bali, Jl. WR Supratman No. 7 Sumerta Kauh, Denpasar Timur, Bali - 80236. Teknik pengumpulan data dilakukan dengan wawancara dan studi dokumen. Analisa data dilakukan dengan menggunakan metode kualitatif dan di sajikan secara deskriftif kualitatif, yaitu memaparkan segala aspek yang berkaitan dengan masalah kemudian mencari solusi berdasarkan penelitian yang di lakukan hingga menemukan suatu kesimpulan.

\section{HASIL DAN PEMBAHASAN}

Peran Anggota Kepolisian Dalmas Polda Bali dalam Penegakan Hukum terhadap Aksi Unjuk Rasa Tolak Reklamasi Teluk Benoa

Kepolisian Daerah Bali atau disebut dengan Polda Bali merupakan kesatuan pelaksana tugas keamanan Negara Republik Indonesia di wilayah teritorial Provinsi Bali. Polda Bali tergolong Polda tipe A yang dipimpin oleh Jendral Bintang Dua atau Inspektur Polisi. Polda Bali terletak di Jalan WR. Supratman No. 7, Kota Denpasar dan membawahi 9 Polres. Dalam pelaksanan tuganya polda Bali memiliki bebrapa unsur yang membidangi tugas dan fungsi masing-masing yang meliputi unsur pimpinan, unsur pengawas, unsur pelaksana tugas pokok, unsur pendukung dan unsur pelaksana tugas kewilayahan (Rahjaya, 2015).

Dilihat dari unsur-unsurnya, sub unsur dalam penanganan unjuk rasa ditangani oleh unsur pelaksana tugas pokok yaitu satuan Sabhara Polda Bali. Sabhara merupakan satuan kepolisian yang bergerak di bidang preventif atau pencegahan dalam menciptakan situasi Kamtibmas di masyarakat.

Satuan Sabhara memiliki 2 sub direktorat yaitu sub direktorat Gasum dan sub direktorat Dalmas. Sub direktorat Dalmas merupakan sub satuan khusus yang dimiliki kepolisian khususnya unsur Sabhara yang khusus menangani unjuk rasa ataupun segala bentuk demonstrasi. Anggota Dalmas Polda Bali terdiri dari 268 personil yang terbagi dalam 3 Kompi, unsur pimpinan dan staf jajaran.

Dalam pelaksanana tugasnya anggota dalmas khusus di bentuk untuk menangani unjuk rasa. Namun dalam aksi unjuk rasa kerap kali teredapat tindakan pelanggran hukum yang mengarah pada tindakan yang anarki. Maka atas dasar Pasal 15 UU No. 9 Tahun 1998, polisi berhak untuk mengambil tindakan berupa membubarkan aksi unjuk rasa tersebut yang kembali ditegaskan dalam pasal 16 UU No. 9 Tahun 1998 yang berbunyi "pelaku atau peserta pelaksanaan penyampaian pendapat di muka umum yang melakukan perbuatan melanggar hukum, dapat dikenakan sanksi hukum sesuai dengan ketentuan peraturan Perundang-Undangan yang berlaku".

Ketentuan-ketentuan yang dimaksud yaitu apabila masa pengunjuk rasa dalam pelaksanannya tidak mengantongi izin dari pihak kepolisian serta melanggar ketentuan dari pasal 6 Undang-Undang No. 9 Tahun 1998 tentang Kemerdekaan Penyampaian Pendapat di Muka Umum yang dijelaskan bahwa Warga negara yang menyampaikan pendapat di muka umum berkewajiban dan bertanggungjawab untuk:

a) menghormati hak-hak dan kebebasan oranglain;

b) menghormati aturan-aturan moral yang diakuiumum;

c) menaati hukum dan ketentuan peraturan perundang-undangan yang berlaku; 
d) menjaga dan menghormati keamanan dan ketertiban umum;dan

e) menjaga keutuhan persatuan dan kesatuanbangsa.

Untuk pelaksanana unjuk rasa tolak reklamasi teluk Benoa sendiri menurut data yang dihimpun dari https://www.forbali.org, terdapat 113 lembaga yang tergabung dalam 36 Desa Adat, LPM, Dusun, Banjar Adat \& STT (Sekaa Truna-Truni/ Lembaga Pemuda Adat), 6 Organisasi Mahasiswa, 20 KomunitasMasyarakat14 Lembaga Swadaya Masyarakatdan Pemuda 37 Seniman \& Musisi menentang akan adanya tolak reklamasi teluk Benoa ini. Penolakan ini umunya dilakukan dengan melakukan demonstrasi di kawasan teluk benoa, Lapangan Puputan Renon dan Kantor Gubernur, Lapangan Puputan Badung serta tempat-tempat lainnnya.

Pada saat terjadinya unjuk rasa tolak reklamasi Teluk Benoa, terdapat tahapan-tahapan penanganan yang dilakukan oleh pihak kepolisian khususnya dari anggota Dalmas Polda Bali sendiri yang meliputi (Aiptu Made Sukrata, Wawancara, 23 Desember 2018):

1. Tahap preemtif

Pada tahap ini anggota Dalmas yang diturunkan yaitu Dalmas awal karena eskalasi masih dalam katagori hijau atau massa pengunuk rasa tolak reklamasi dalam keadaan tertib. Pada saat ini anggota Dalmas mengawal setiap kegiatan yang dilakukan oleh massa pengunjuk rasa sambil memberikan himbauan melalui negosiator agar situasi tetap bertahan tertib.

2. Tahap preventif

Pada tahap ini situasi sudah mengarah ke kuning atau mengarah pada indikasi tindakan anarkis. Anggota Dalmas melakukan lintas ganti dengan menurunkan Dalmas lanjut dengan tetap diiringi oleh pemberian himbauan dari tim negosiator. Pada tahap ini anggota Dalmas telah siap dengan perlengkapan Dalmas guna antisipasi massa mengarah pada eskalasi merah.

3. Tahap represif

Pada tahap ini massa telah dalam katagori merah atau melakukan aksi anarkis. Tim negosiator tidak lagi memberikan himbauan, dan untuk Dalmas melakukan lintas ganti dengan Brimob, namun tetap mem-back-up di sisi kanan maupun kiri guna membantu pergerakan pengamanan. Pada tahap ini anggota telah memiliki izin untuk mengambil tindakan hukum sesuai dengan penerapan UndangUndang dan prosedur yang berlaku.

Aksi unjuk rasa tolak reklamasi Teluk Benoa sesungguhnya telah dimulai sejak isu penerbitan Surat Keputusan (SK) Gubernur Bali, Made Mangku Pastika, Nomor 2138/02-C/HK/2012 tentang Izin dan Hak Pemanfaatan, namun dalam pelaksanaanya penolakan-penolakan yang timbul hanya berupa pernyataan serta petisi-petisi dari masyarakat kawasan Teluk Benoa dan sekitarnya. Setelah penerbitan Surat Keputusan (SK) Gubernur Bali, Made Mangku Pastika, Nomor 2138/02-C/HK/2012 tentang Izin dan Hak Pemanfaatan yang diikuti dengan Kementerian Kelautan dan Perikanan (KKP) mengesahkan Peraturan Menteri 17/Permen-KP/2013 yang mengizinkan reklamasi di zona konservasi non-inti pada 3 Juli 2013, mulai timbul penolakan nyata berupa unjuk rasa-unjuk rasa yang timbul dari kalangan masyarakat Bali. Ini diawali dengan unjuk rasa oleh masyarakat Tanjung Benoa dan sekitarnya hingga mengarah pada penolakan oleh berbagai komponen masyarakat Bali yang jauh dari pesisir pantai. Seiring berjalannya unjuk rasa tolak reklamasi Teluk Benoa pada tahun 2014 tepatnya pada 30 Mei 2014, Presiden RI saat itu Soesilo Bambang Yudhoyono menerbitkan Perpres 51/2014 yang mengizinkan reklamasi di wilayah konservasi Teluk Benoa. Hal ini menjadi tonggak awal dari meningkatnya aksi unjuk rasa tolak reklamasi ini.

Adapun aksi unjuk rasa tolak reklamasi Teluk Benoa yang dimulai dari tahun 2013-2018 di paparkan dalam tabel sebagai berikut:

Tabel 1 Data Kasus Aksi Unjuk Rasa Tolak Reklamasi Teluk Benoa Tahun 2013-2018

\begin{tabular}{|c|c|}
\hline Tahun & Jumlah \\
\hline 2013 & 9 \\
\hline 2014 & 10 \\
\hline 2015 & 7 \\
\hline 2016 & 22 \\
\hline 2017 & 7 \\
\hline 2018 & 8 \\
\hline Total & 63 \\
\hline
\end{tabular}


Sumber: Subdit Dalmas Direktorat Sabhara Polda Bali

Berdasarkan data yang diperoleh penulis pada tanggal 21 Desember 2018 di atas, presentasi aksi unjuk rasa tolak reklamasi teluk benoa dari 2013 sampai 2018 berjumlah 63 kasus, dan dalam beberapa kasus tersebut terdapat kasus-kasus dalam pelaksanaan unjuk rasa tolak reklamasi Teluk Benoa yang cenderung melanggar ketentuan hukum yang meliputi bentuk ancaman terhadap Gubernur Made Mangku Pastika pada tanggal 16 Februari 2014 oleh aktifis Jaringan Aksi Tolak Reklamasi (Jalak) Sidakarya. Aksi bakar ban dilakukan oleh masa pengunjuk rasa pada tanggal 15 Agustus 2016, aksi blokade jalan oleh masa pengunjuk rasa yang tidak mengantongi izin melakukan unjuk rasa pada tangal 20 Mei 2016, serta aksi penurunan bendera merah putih yang menggantinya dengan bendera lain, di mana aksi ini berlangsung pada tanggal 25 Agustus 2016 dana ksi ini banyak dikecam oleh komponen masyarakat yang mengakibatkan 2 aktifis For Bali diperiksa oleh penyidik Polda Bali.

\section{Faktor-Faktor yang Menghambat Pelaksanaan Penanganan Unjuk Rasa Tolak Reklamasi Teluk Benoa oleh Anggota Kepolisian Dalmas Polda Bali}

Pada pelaksanaan kegiatan unjuk rasa tolak reklamasi teluk Benoa terdapat beberapa kendala atau factor-faktor penghambat pelaksanaan penananganan unjuk rasa oleh anggota Dalmas Polda Bali, faktor tersebut terbagi menjadi factor internal maupun eksternal yang meliput:

1. Faktor Internal

a) Terdapat anggota Dalmas yang kurang paham akan penerapan aturan serta prosedur penangan unjuk rasa;

b) Kadang kala anggota di lapangan tidak dapat mengontrol emosi terhadap perkataan maupun perbuatan yang dilakukan oleh massa pengunjuk rasa;

c) Kadangkala terjadi keterlambatan informasi yang didapatkan saat terjadinya unjuk rasa, sehingga terdapat beberapa penanganan unjuk rasa tolak reklamasi yang dilakukan secara tergesa-gesa tanpa mempersiapkan alat yang matang;

d) Dalam unjuk rasa tolak reklamasi Teluk Benoa kerap kali dilakukan dengan berjalan kaki menuju titik satu ke titik yang lainnya dengan estimasi jarak yang cukup jauh sehingga menyulitkan anggota memberikan pengamanan sekaligus mengatur lalu lintas yang termasuk melaksanakan rekayasa lalulintas sehingga kegiatan unjuk rasa dapat berjalan dengan aman dan lancar tanpa terlalu memberatkan dan menggangu aktifitas masyarakat lainnya (Brigadir Nyoman Agus Artawan, Wawancara, 25 Desember 2018).

2. Faktor Eksternal

a) Perlunya peningkatan terhadap pemahaman serta penerapan hukum oleh masayarakat sehingga dapat meminimalisir aksi unjuk rasa anarkis yang berujung pada pembakaran ban ataupun penangkapan oknum pengunjuk rasa yang menyalahi aturan pelaksanaan unjuk rasa, khusunya dalam pelaksanaan unjuk rasa tolak reklamasi Teluk Benoa;

b) Dalam penanganan unjuk rasa tolak reklamasi teluk benoa kerap kali massa pengunjuk rasa yang menuju titik kumpul pelaksanaan unjuk rasa tolak reklamasi teluk benoa ini mengggunakan kendaraannya secara ugal-ugalan, tidak menggunakan helem serta secara bergerombolan di jalan melanggar lalu lintas menuju lokasi titik kumpul tersebut. Hal ini kerap kali menjadi kemacetan serta gangguan lalu lintas bagi jalur masyarakat yang lainnya (Brigadir Nyoman Agus Artawan, Wawancara, 25 Desember 2018);

c) Dalam pelaksanaan unjuk rasa tolak reklamasi Teluk Benoa, beberapa kali massa tidak bisa mengendalikan emosinya sehingga melakukan tindakan-tindakan serta ucapan-ucapan yang cenderung menimbulakan rasa emosi bagi anggota Dalmas yang memberikan pengamanan;

d) Dalam pelaksanana unjuk rasa, kordinasi pelaksanaan di lakukaan secara mendadak.

Untuk menanggulangi faktor-faktor tersebut Dalmas polda Bali memiliki cara-cara serta bentuk antisipasi untuk meminimalisir kejadian yang tidak diinginkan, cara-cara tersebut berupa:

1. Dalam persiapannya, setiap hari anggota Dalmas Polda Bali melaksanakan kegiatan-kegiatan Dalmas yang diperuntukan untuk peningkatan Teknik dalam menangani segala jenis unjuk rasa termasuk unjuk rasa tolek reklamasi Teluk Benoa ini.

2. Mempersiapkan peralatan Dalmas yang apabila sewaktu-waktu dibutuhkan. Kesiapan ini berupa pembersihan dan pengecekan bahan bakar yang dilalukan setiap hari serta pengecekan keberfungsian mesin yang dilakukan setiap 1 bulan sekali. Bila terjadi kendala dalam suatu 
kendaraan agar segera di perbaiki sehingga tidak menimbulkan permasalahan ketika digunakan saat pengamanan unjuk rasa.

3. Diselenggarakan kegiatan Forum Group Diskusi yang dilakukan oleh anggota polri dengan kordinator massa pengunjuk rasa tolak reklamasi serta mengikut sertakan berbagai elemen masyarakat agar pelaksanana unjuk rasa berjalan sesuai dengan ketentuan, dan apabila terjadi unjuk rasa yang di luar ketentuan, pihak kepolisian memberikan larangan langsung agar tindakan tersebut tidak dilakukan kembali.

4. Pimpinan Dalmas secara langsung memberikan teguran dan arahan apabila terdapat anggotanya dalam pelaksanaan pengamanan unjuk rasa tolak reklamasi Teluk Benoa dan jika sudah melakukan tindakan kepolisian di luar ketentuan.

\section{SIMPULAN DAN SARAN \\ Simpulan}

Berdasarkan hasil dan pembahasan di atas, simpulan yang dapat dibuat adalah peran Kepolisian Dalmas Polda Bali dalam menegakan hukum terhadap aksi unjuk rasa tolak reklamasi Teluk Benoa dilakukan berdasarkan tindak pre-emtif, preventif serta tindakan represif yang berpedoman pada peraturan perundang-undangan serta peraturan-peraturan Kapolri tentang penanganan unjuk rasa. Selain itu, faktor-faktor yang menghambat pelaksanaan unjuk rasa tolak reklamasi Teluk Benoa oleh anggota kepolisian Dalmas Polda Bali meliputi faktor internal dan eksternal. Faktor internal merupakan faktor dari anggota Dalmas sendiri baik dari segi mental, profesionalisme, maupun pengetahuan mengenai penangann unjuk rasa. Sedangkan faktor eksternal umumnya berupa massa pengunjuk rasa yang kurang memahai ketentuan-ketentuan yang berlaku dalam pelaksanan unjuk rasa.

\section{Saran}

Selain simpulan, ada beberapa saran yang perlu disampaikan berdasarkan hasil penelitian ini, yaitu: pertama, penegakan hukum dalam penanganan unjuk rasa menjadi salah satu tugas bagi anggota Dalmas Polda Bali, maka anggota Dalmas Polda Bali harus bertindak tegas dengan memeberikan penegakan hukum sesuai dengan prosedur dan ketentuan yang berlaku. Kedua, untuk menangani faktor-faktor penghambat pelaksanana unjuk rasa, diharapkan agar anggota Dalmas polda Bali meningkatan kemampuan sumber daya manusia melalui pelatihan yang telah rutin dilaksanakan dengan intensitasnya dan pertimbangkan kebutuhan di lapangan secara matang. Selain itu, sebagai bentuk antisipasi diperlukan peningkatan sarana dan prasarana dengan mempertimbangkan perkembangan ilmu pengetahuan dan teknologi, sehingga peralatan dan perlengkapan yang dimiliki mampu menghadapi tantangan tugas dilapangan untuk ke depannya.

\section{DAFTAR PUSTAKA}

Priyantoko, G. (2016). Penerapan Diskresi Kepolisian dalam Penanganan Unjuk Rasa. DE LEGA LATA: Jurnal Ilmu Hukum, 1(1), 109-136.

Rahjaya. (2015). Divisi Pendidikan Pembentukan BRIGADIR Polri. Jakarta: Dalmas.

Saputro, L. (2015). Diskresi Anggota Kepolisian Negara Republik Indonesia dalam Penanganan Aksi Unjuk Rasa dan Implikasinya terhadap Ketahanan Wilayah (Studi di Kepolisian Resort Kota Yogyakarta). Jurnal Ketahanan Nasional, 21(2), 89-106.

Sudiarta, K., Hendrawan, I. G., Putra, K. S., \& Dewantama, I. M. I. (2013). Laporan Kajian Modeling Dampak Perubahan Fungsi Teluk Benoa untuk Sistem Pendukung Keputusan (Decision Support System) dalam Jejaring KKP Bali.

Surawan, A. (2016). Penegakan Hukum terhadap Demonstran yang Melakukan Pengrusakan Fasiltas Negara Sesuai dengan Pasal 408 KUHP di Wilayah Hukum Resort Pontianak Kota. Gloria Yuris, 4(3).

Sutrisno. (2016). Sosiologi Kepolisian: Relasi Kuasa Polisi dengan Organisasi Masyarakat Sipil Pasca Orde Baru (1st ed.).

Syahbana, M. R. (2013). Penerapan Prosedur Tetap Polri dalam Penanggulangan Unjuk Rasa Anarki. Jurnal Ilmu Hukum Legal Opinion, 1(2), 1-22. Retrieved from

Syamsir. (2015). Demokratisasi Hak Berpikir dan Berkreasi Warga Negara di Indonesia. Jurnal Inovatif, 8(1), $115-133$.

Wiranata, I. M. A., \& Siahaan, H. (2019). Konstruksi Identitas Kolektif Warga Desa Adat dalam Gerakan Tolak Reklamasi Teluk Benoa di Bali. Jurnal Kajian Bali (Journal of Bali Studies), 9(2), 407-428. 
Jurnal Konstruksi Hukum

Vol. 1, No. 2, 2020

Yuliawati, Y. (2019). Penegakan Hukum terhadap Aksi Unjuk Rasa Mahasiswa yang Menimbulkan Kerusakan pada Fasilitas Umum dalam Tinjauan Krimonologi (Universitas Ahmad Dahlan).

https://www.forbali.org/id/tentang-kami/ 